\title{
Meningeal Melanoma
}

National Cancer Institute

\section{Source}

National Cancer Institute. Meningeal Melanoma. NCI Thesaurus. Code C5317.

A melanoma that arises from leptomeningeal melanocytes. 